\title{
LITIASIS GIGANTE EN DERIVACIÓN URINARIA TIPO BRICKER. UROPATÍA OBSTRUCTIVA COMO FORMA DE PRESENTACIÓN
}

\author{
J.A. GÓMEZ PASCUAL, J.M. DEL ROSAL SAMANIEGO, E. GARCÍA GALISTEO, \\ R. BONILLA PARRILLA, J. RAMOS TITOS, A. ALVARADO RODRÍGUEZ, \\ F. BLANCO REINA, V. BAENA GONZÁLEZ
}

Servicio de Urología. Hospital Regional de Málaga. Complejo Hospitalario Carlos Haya. Málaga.

Actas Urol Esp. 27 (3): 240-243, 2003

\section{RESUMEN}

"LITIASIS GIGANTE EN DERIVACIÓN URINARIA TIPO BRICKER. UROPATÍA OBSTRUCTIVA COMO FORMA DE PRESENTACIÓN"

El intestino es usado en cirugía urológica para sustituir la vejiga a modo de un conducto que drene orina a la pared abdominal o remodelado para formar una vejiga de sustitución o ampliación.

Muchos factores contribuyen a la formación de litiasis siendo los más importantes el éstasis urinario, producción de moco y la bacteriuria. Las alteraciones metabólicas inducidas por la exposición de segmentos intestinales en el tracto urinario promueve la formación de cálculos de estruvita, oxalato cálcico y fosfato cálcico.

Generalmente, la mayoría de pacientes con litiasis en derivaciones urinarias, pueden ser tratados con técnicas mínimamente invasivas. La extracción mediante cirugía abierta es considerada cuando otras modalidades de tratamiento no pueden ser efectuadas de forma segura y expeditiva.

PALABRAS CLAVE: Derivación urinaria. Litiasis. Tratamiento.

\section{ABSTRACT}

"GIANT STONE IN BRICKER URINARY DIVERSION PRESENTING AS OBSTRUCTIVE UROPATHY"

Bowel is used in urological surgery to replace the bladder, either as a conduit to drain urine to the abdominal wall as a urinary stoma or refashioned to form a substitute bladder.

Many factors contribute to stone formation, being urinary stasis, mucus production and bacteriuria the most important. Metabolic changes induced by exposure of segments of the alimentary tract to urine promote struvite, calcium oxalate and calcium phosphate stone formation.

Generally, the majority of patients with stones in a urinary diversion can be treated with minimally invasive techniques. Open surgical removal is considered when other modality of treatments cannot be accomplished safely and expediously.

KEY WORDS: Urinary diversion. Lithiasis. Treatment.

$\mathrm{L}$ a formación de litiasis en las derivaciones urinarias que emplean intestino constituye una complicación a largo plazo de este tipo de técnicas quirúrgicas cuando se utilizan en cirugía oncológica o por necesidades de ampliación de la capacidad vesical. El factor fisiopatológico desencadenante más importante es el éstasis urinario, que usualmente se ve favorecido por la presencia de moco intestinal e infección urinaria. Su frecuencia oscila entre el $10 \%$ y el $50 \%$ según series ${ }^{1}$. El tratamiento, habitualmente mediante acceso endoscópico, puede variar según el tamaño de la misma y el tipo de derivación con la que nos encontramos. 


\section{CASO CLÍNICO}

Presentamos el caso de un varón de 61 años sometido a cistoprostatectomía radical y ureteroileostomía cutánea tipo Bricker en 1987 por tumor vesical infiltrante (Estadio T2 GIII de la clasificación TNM).

Entre sus antecedentes cabe destacar una alergia a betalactámicos e hidrocelectomía bilateral. Tras 5 años sin revisiones de forma voluntaria, acude al Servicio de Urgencias por un cuadro de desorientación, vértigo, decaimiento general y pérdida de peso destacando a la exploración física una delgadez importante, palidez de piel-mucosas y desorientación témporo-espacial como datos más llamativos. La auscultación cardiopulmonar fue normal y el abdomen blando, depresible con urostomía de aspecto normal. La palpación digital dentro del asa de urostomía reveló una estenosis anular.

La bioquímica sanguínea reveló una creatinina de $4,23 \mathrm{mg} / \mathrm{dl}$ y una urea de $144 \mathrm{mg} / \mathrm{dl}$. El sedimento urinario mostró: 100-150 hematíes/campo y 10-15 leucocitos/campo.

La radiografía simple de abdomen objetivó una imagen de densidad calcio sobre hipogastrio, posiblemente en el asa de la urostomía. La ecografía abdominal urgente mostró una ectasia renal bilateral grado III/IV, con cortical hiperecogénica y una imagen hiperrefringente a nivel del asa ileal (Fig. 1). Se decidió la colocación de una nefrostomía bilateral, evidenciándose salida de orinas purulentas (Fig. 2). Tras la colocación de las nefrostomías el paciente comienza con diuresis

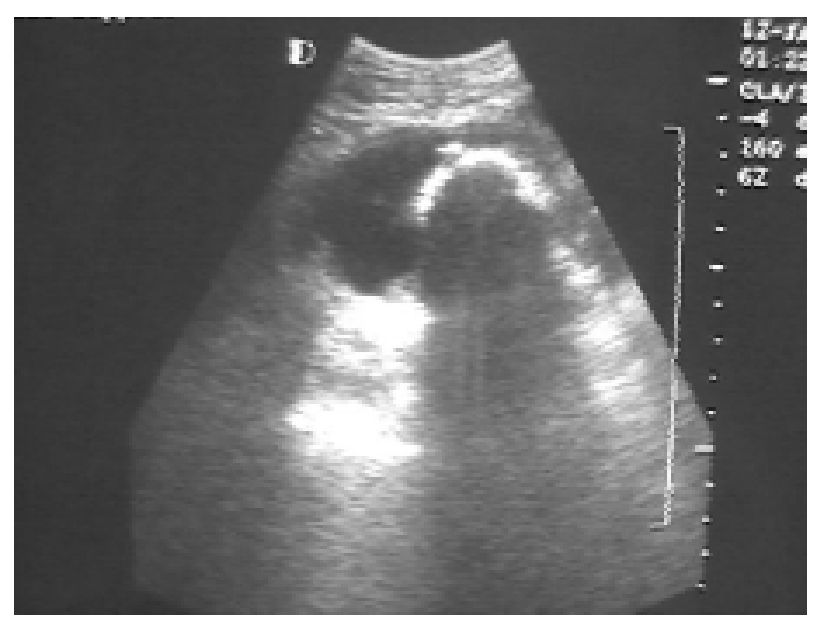

FIGURA 1. Imagen de ecografía abdómino-pélvica donde se observa una gran litiasis con bordes espiculados a nivel de la neovejiga.

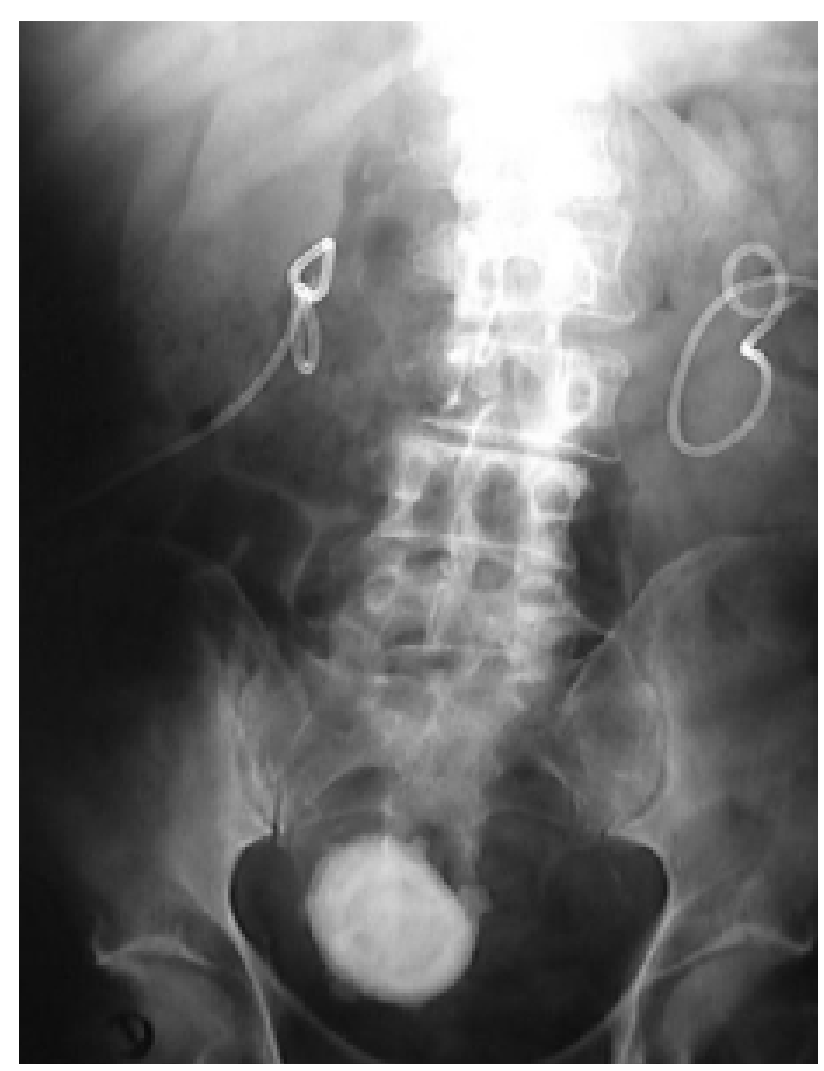

FIGURA 2. Radiografia simple de abdomen realizada tras colocación de nefrostomía percutánea bilateral donde observamos una imagen de densidad calcio de grandes dimensiones sobre hipogastrio.

abundante y normalización progresiva de cifras de urea y creatinina hasta unos valores de $76 \mathrm{mg} / \mathrm{dl}$ y $1,41 \mathrm{mg} / \mathrm{dl}$ respectivamente.

Durante su estancia hospitalaria se realizó una pielografía anterógrada bilateral que mostró buen paso de contraste con ectasia II-III/IV de ambos sistemas colectores hasta el asa ileal e imagen de defecto de repleción en dicha asa, no pudiendo diferenciar entre ocupación del mismo por detritus u hongos o incluso cálculo de gran tamaño. Posteriormente se realizó scanner abdomino-pélvico que reveló dilatación de pelvis renal derecha $\mathrm{y}$ en los cortes inferiores a la misma un área de aumento de densidad redondeada compatible con litiasis. Con el diagnóstico de litiasis de gran tamaño en asa de urostomía se desestima tratamiento endoscópico y se opta por la intervención quirúrgica abierta que se realizó a las dos semanas del inicio del cuadro, una vez estabilizada la situación clínica del paciente, practicándose una laparotomía media infraumbilical con liberación de asas 
hasta localizar el asa ileal donde se alojaba una litiasis de 10 x $15 \mathrm{~cm}$ que se extrajo y cuyo análisis posterior evidenció una composición de fosfato amónico-magnésico (Fig. 3). El post-operatorio cursó con síndrome febril e íleo paralítico que a los 4 días se solucionó con tratamiento médico, siendo dado de alta el paciente a la semana de la intervención. La radiografía simple de abdomen previa al alta mostró la ausencia completa de la litiasis causante de este cuadro.

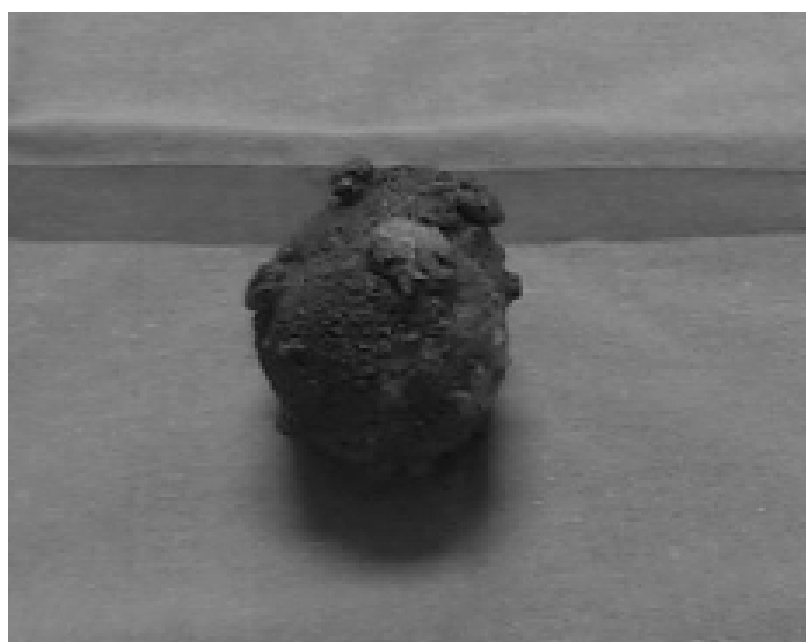

FIGURA 3. litiasis de $15 \times 10 \mathrm{~cm}$ con bordes espiculados. Su análisis objetivó una composición de estruvita.

\section{DISCUSIÓN}

Las complicaciones a largo plazo de las derivaciones urinarias son variadas, destacando, entre otras, la formación de litiasis. El íleon y colon son los segmentos intestinales más comúnmente empleados para las sustituciones vesicales y la continua función secretora y absortiva contribuye al origen de estas complicaciones ${ }^{1}$.

Diversos factores contribuyen a la génesis de un cálculo en un segmento intestinal; considerándose el éstasis urinario el factor etiopatogénico principal; otros factores que contribuyen en mayor o menor medida son la presencia de moco intestinal, utilización de suturas mecánicas e infección del tracto urinario, ésta última con una incidencia del $20 \%{ }^{2}$. Otro factor litogenético en los pacientes con derivaciones urinarias intestinales es la acidosis metabólica debida a la pérdida de bicarbonato y reabsorción de solutos urinarios como amonio, cloro e hidrogeniones. La acidosis puede provocar hipercalciuria inhibiendo la absorción de calcio en la nefrona. También induce hipocitraturia ${ }^{3}$ que es un conocido factor de riesgo para la formación de litiasis cálcicas y de estruvita. La acidosis metabólica produce desmineralización ósea mediante un mecanismo tampón que libera calcio y aumenta su excrección $n^{4,5}$. Todos estos factores contribuyen que en estos pacientes existan más probabilidades de desarrollar litiasis urinarias. Algunos autores han recogido que el riesgo de formar litiasis nuevas a los cinco años es del 63,3\% y fue significativamente mayor en pacientes con bacteriuria recurrente, debiendo considerar el uso de profilaxis antibiótica a largo plazo en estos pacientes ${ }^{6}$. El tiempo de aparición de estas litiasis también es variable y puede oscilar desde 6 meses hasta varios años después. Su frecuencia varía según las series del 10 al 50\% y el índice de recurrencia es alto, siendo 5-10 veces más frecuente en aquellos que tienen bacteriuria recurrente y precisan de autocateterismos de forma intermitente ${ }^{1}$. Presentan menor riesgo las formas ortotópicas y aquellas que permiten el vaciamiento vesical espontáneo ${ }^{2}$. Su forma de presentación es variable $\mathrm{y}$ va desde dolor a nivel abdominal o en flanco, infecciones del tracto urinario, hematuria macroscópica, dificultades en el autosondaje y alteraciones en el mecanismo de continencia ${ }^{2,4}$.

En nuestro caso, pensamos que la estenosis anular objetivada en la exploración pudo ser la causa del vaciamiento urinario ineficaz de este paciente, contribuyendo a la formación la litiásica. En este paciente el tamaño de la litiasis contribuyó a desarrollar una uropatía obstructiva como forma de presentación.

Generalmente, la mayoría de los pacientes con litiasis localizadas en derivaciones urinarias pueden ser tratados mediante técnicas mínimamente invasivas $^{6,7}$, la litotricia extracorpórea con ondas de choque (LEOC) se reserva para pacientes con accesos difíciles a las litiasis ${ }^{4}$. Claus et al. ${ }^{8}$ utilizaron con éxito la LEOC en dos pacientes con reservorio de tipo Indiana como terapéutica no invasiva y sin peligro para la continencia del reservorio. Los reservorios continentes suelen requerir cirugía abierta o incluso un abordaje percutáneo ${ }^{9}$ dado que la instrumentación prolongada o repetida podría dañar el mecanismo de continencia y los posibles fragmentos residuales contribuirían a la 
recurrencia en cuanto a su formación ${ }^{4,5}$. En el caso de la ureteroileostomía tipo Bricker la vía de abordaje electiva sería de forma endoscópica a través del propio estoma para la extracción de la litiasis. La vía abierta se reserva para litiasis de gran tamaño donde la fragmentación en su interior podría ocasionar lesiones del segmento intestinal.

Debido a que muchos pacientes con derivaciones urinarias y litiasis permanecen asintomáticos, como en nuestro caso, recomendamos la realización de estudios de imagen periódicos como radiografía simple y ecografía ${ }^{8}$, así como la ingesta abundante de líquidos y la irrigación periódica del reservorio para eliminar moco y cristales ${ }^{5}$. Debería considerarse tratamiento con ácido acetohidroxámico en pacientes con infecciones urinarias de repetición y antecedentes de litiasis en derivaciones urinarias. Así mismo debería considerarse el estudio metabólico de aquellos pacientes con litiasis de calcio y mixtas (estruvita-calcio), dado que un número significativo de éstos tendrá una anomalía metabólica susceptible de ser tratada.

\section{REFERENCIAS}

1. MUNDY AR.: Metabolic complications of urinary diversion. The Lancet 1999; 353: 1813-1814.

2. NURSE DE, MCINERNEY PD, THOMAS PJ, MUNDY AR.: Stones in enterocystoplasties. Br J Urol 1996; 77 (5): 684-686.

3. SCHNEIDER HJ, BOCKHORN V.: Metabolic studies during urinary diversion by way of the small intestine. Z Urol and Nephrol 1979; 72 (5): 365-374.
4. ASSIMOS DEAN G.: Nephrolithiasis in patients with urinary diversion. $J$ Urol 1996; 155 (1): 69-70.

5. TERAI AKITO, UEDA TOMOHIRO, KAKEHI YOSHIYUKI, TERACHI YOSHIRO, ARAI YOICHI, OKADA YUSAKU, YOSHIDA OSAMU.: Urinary calculi as a late complication of the Indiana continent urinary diversion: comparison with the Kock pouch procedure. $J$ Urol 1996; 155 (1): 66-68.

6. COHEN TODD D, STREEM STEVAN B, LAMMERT GARY.: Long term incidence and risks for recurrent stones following contemporary management of upper tract calculi in patients with a urinary diversion. $J$ Urol 1996; 155 (1): 62-65.

7. GINSBERG D, HUFFMAN JL, LIESKOVSKY G, BOYD S, SKINNER DG.: Urinary tract stones: a complication of the Kock pouch urinary diversion. J Urol 1991; 145 (5): 956-959.

8. CLAUS C, JORION JI, LIBON E.: Continent urinary diversion and calculus. Act Urol Bel 1997; 65 (4): 3337.

9. ONISHI N, TAKAMURA C, WAKABAYASHI A, KATHKO Y, MATSUURA T, KOHRI K, AKIYAMA T, KURITA T.: Percutaneous nephro-ureterolithotripsy in patients after urinary diversion or reconstruction using the intestine: report of 5 cases. Act Urol Jap 1989; 35 (3): 393-396.

Dr. J.A. Gómez Pascual Servicio de Urología. Hosp. Civil Complejo Hospitalario Carlos Haya Plza. Hospital Civil, s/n 29009 Málaga

(Trabajo recibido el 15 abril de 2002) 